\title{
Congenital and Acquired Lutembacher's Syndrome Presenting in Two Adults
}

\author{
Umut Kocabas, Ugur Onsel Turk' \\ Department of Cardiology, Edremit State Hospital, Balikesir, ${ }^{1}$ Center for Drug Research and Development and Pharmacokinetic Applications, School of Medicine, \\ Ege University, Izmir, Turkey
}

\section{Abstract}

The coexistence of atrial septal defect (ASD) and mitral stenosis (MS) is defined as Lutembacher's syndrome (LS). LS was originally defined as the development of MS in a patient having a congenital ASD diagnosis. However, as the percutaneous interventions for MS have become widespread, the persistence of associated iatrogenic ASDs caused has given rise to a different form of the disease. LS may occur as spontaneous or iatrogenic ASD concomitant with acquired MS; this form is known as "acquired LS." This report presents two cases illustrating congenital LS and "acquired LS."

Keywords: Atrial septal defect, congenital heart disease, Lutembacher's syndrome, mitral stenosis, valvular heart disease

\section{INTRODUCTION}

Lutembacher's syndrome (LS) occurs as a rare combination of congenital secundum atrial septal defect (ASD) and an acquired mitral stenosis (MS). ${ }^{[1]}$ Alternatively, LS may occur as spontaneous or iatrogenic ASD concomitant with acquired MS; this form is known as "acquired LS". ${ }^{[2]}$ The literature also describes "reverse LS," which is characterized by a predominant pulmonary-to-systemic or right-to-left shunting of blood in the context of an ASD and severe tricuspid stenosis. ${ }^{[3]}$ This report presents two cases illustrating congenital LS and "acquired LS."

\section{Case Reports}

\section{Case presentation 1}

A 53-year-old female was referred to our cardiology clinic with shortness of breath, orthopnea, and paroxysmal nocturnal dyspnea. The patient history showed percutaneous mitral balloon valvuloplasty (PMBV) for rheumatic MS in 1998. Physical examination revealed a systolic murmur in the mesocardiac area and a diastolic murmur in the apical area. The 12-lead electrocardiography showed atrial fibrillation with rapid ventricular response. Transthoracic echocardiography found that the left ventricular ejection fraction was preserved and revealed calcified and thickened mitral valve with giant left

\begin{tabular}{|l|l|}
\hline \multicolumn{3}{c|}{ Access this article online } \\
\hline Quick Response Code: & Website: \\
& http://www.ijcva.com \\
\hline
\end{tabular}

atrium, severe mitral regurgitation, severe eccentric tricuspid regurgitation with a pulmonary systolic pressure of $80 \mathrm{mmHg}$ and a 5-mm sized, and mild left-to-right shunting across an ostium secundum ASD [Figure 1a-e]. The Qp/Qs ratio was 1.48. Mitral valve area (MVA) was $1.1 \mathrm{~cm}^{2}$ according to the pressure half-time (PHT) method [Figure 1f], and the mean diastolic transvalvular mitral valve gradient was $13 \mathrm{mmHg}$. To minimize the risk of miscalculations due to decreased left atrial pressure and diastolic mitral pressure gradient, which is characteristic of ASD, MVA was also calculated as $0.9 \mathrm{~cm}^{2}$ with the planimetry method. The patient having no ASD in previous echocardiography reports and having a history of PMBV was diagnosed with "acquired LS." This is thought to have arisen iatrogenically due to PMBV in 1998 and/or spontaneously due to extreme tension of the left atrium. Following refusal of cardiac surgery, the patient was discharged with warfarin, bisoprolol, digoxin, and furosemide therapy and a program of intensive follow-up. In follow-up program, warfarin dose titrated according to international normalized ratio and

Address for correspondence: Dr. Umut Kocabas, Department of Cardiology, Baskent University Faculty of Medicine, Istanbul, Turkey. E-mail: umutkocabas@hotmail.com

This is an open access journal, and articles are distributed under the terms of the Creative Commons Attribution-NonCommercial-ShareAlike 4.0 License, which allows others to remix, tweak, and build upon the work non-commercially, as long as appropriate credit is given and the new creations are licensed under the identical terms.

For reprints contact: reprints@medknow.com

How to cite this article: Kocabas U, Turk UO. Congenital and acquired Lutembacher's syndrome presenting in two adults. Int J Cardiovasc Acad 2018;4:59-61. 

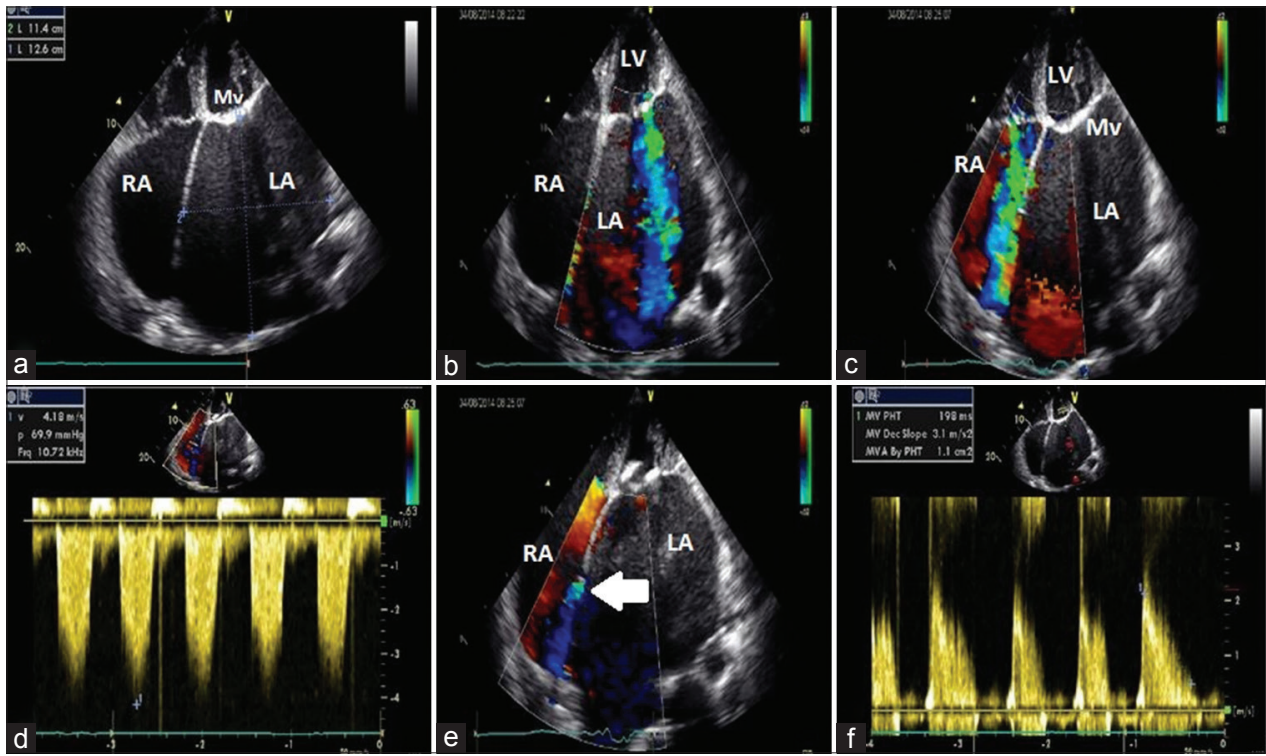

Figure 1: Transthoracic echocardiography apical 4-chamber view image showing calcified and thickened mitral valve with giant left atrium (a), severe mitral regurgitation (b), severe eccentric tricuspid regurgitation with a pulmonary systolic pressure of $80 \mathrm{mmHg}$ (c and d) and mild left-to-right shunting across an ostium secundum atrial septal defect (e, arrow) and mitral valve area was $1.1 \mathrm{~cm}^{2}$ according to the pressure half-time method (f). RA: Right atrium, La: Left atrium, LV: Left ventricle, MV: Mitral valve

bisoprolol and digoxin doses titrated according to heart rate, blood pressure, and serum digoxin level in every 3 weeks.

\section{Case presentation 2}

A 48-year-old female patient was referred to our cardiology clinic with palpitation and dyspnea. Her medical history was unremarkable. On physical examination, a diastolic murmur of $2 / 6^{\circ}$ in the apical area and a systolic murmur in the mesocardiac area were auscultated. The 12-lead electrocardiography showed sinus rhythm with frequent atrial premature complexes, and $P$ wave morphology was consistent with "P mitrale." Transthoracic echocardiography showed thickened, fibrotic mitral valves with a valve area of $1.6 \mathrm{~cm}^{2}$ using the planimetry method [Figure $2 \mathrm{a}$ and $\mathrm{b}$ ]. Doppler echocardiography revealed mild mitral and tricuspid regurgitation, a 4-mm sized, left-to-right shunting across an ostium secundum ASD [Figure $2 \mathrm{c}$ and $\mathrm{d}$ ]. The patient was diagnosed with LS with the coexistence of MS and ASD. The Qp/Qs ratio was 1.22 and systolic pulmonary arterial pressure was $38 \mathrm{mmHg}$. The patient was discharged with metoprolol therapy and a program of echocardiographic follow-up in every 6 months.

\section{DISCUSSION}

The coexistence of congenital ASD and acquired MS is defined as LS. ${ }^{[1]} \mathrm{LS}$ is a rare condition with a reported incidence of 0.001 in one million. Since both ASD and MS are frequently found in women, LS also occurs more commonly among women. ${ }^{[4]}$ Hemodynamic interactions between ASD and MS are challenging. As in LS, one lesion can alter the clinical and hemodynamical effects of the other lesion. Clinical and hemodynamic interactions are dependent on three of the following properties: the diameter of ASD, severity of MS, and compliance of the right ventricle. ${ }^{[5]}$ In a patient with MS, a large ASD provides an additional outflow point for the left atrium. The left atrium is decompressed via ASD, resulting in decreased left-atrial and pulmonary capillary pressures. Consequently, symptoms observed in isolated MS patients, such as exertional dyspnea, orthopnea, and paroxysmal dyspnea, occur in the later phases of the disease. Blood flow through the mitral valve is decreased due to an increase in the left-to-atrial shunt. The result of this effect is a decrease in the severity of mitral murmur and presystolic accentuation in patients having sinus rhythm, and the opening snap cannot be auscultated. ${ }^{[6]}$ On the other hand, increased left-atrial pressure due to MS progressively increases the left-to-right shunt via ASD. In particular, in the presence of a large ASD, the right ventricular volume and pressure overload will increase over time, causing the right ventricle to dilate, leading to pulmonary hypertension and right-heart failure ${ }^{[2]}$ In summary, the coexistence of MS and ASD has a distinct course as compared with isolated MS. The existence of ASD in an MS patient can mimic the symptoms and auscultatory findings of the disease. Increased left-atrial pressure due to MS increases the left-to-atrial shunt, causing early right-heart failure and pulmonary hypertension.

LS was originally defined as the development of MS in a patient having an ASD diagnosis. However, as the percutaneous interventions for MS have become widespread, the persistence of associated iatrogenic defects caused has given rise to a different form of the disease. This condition, "acquired LS," may result from two different scenarios. In the first scenario, in isolated MS patients, an "iatrogenic ASD" may occur due to PMBV, which is performed through atrial septal puncture by 


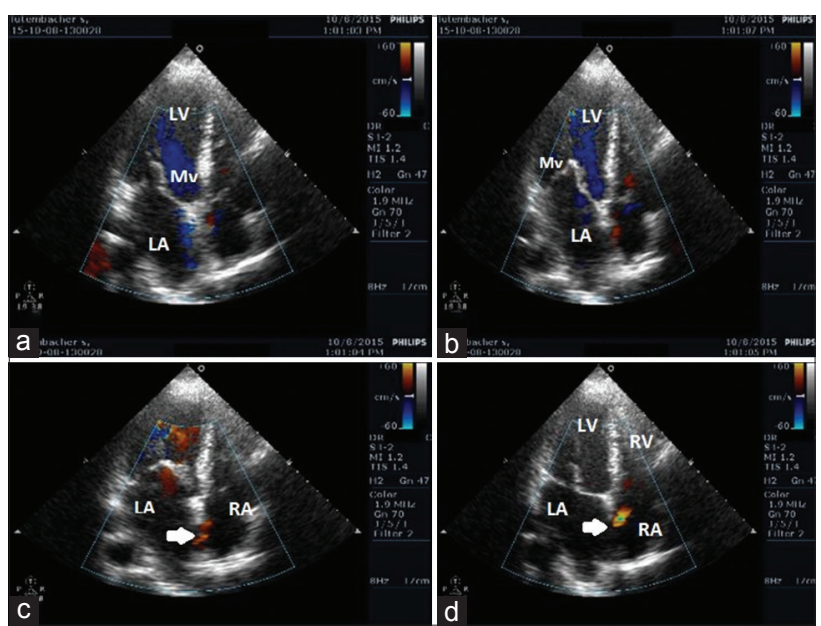

Figure 2: Transthoracic echocardiography apical 4-chamber view image showing thickened, fibrotic, and stenotic mitral valves (a and b), Doppler echocardiography revealed left-to-right shunting across an ostium secundum atrial septal defect (c and d, arrow). RA: Right atrium, LA: Left atrium, RV: Right ventricle, LV: Left ventricle, MV: Mitral valve

the transseptal approach. ${ }^{[2]}$ In a trial by Yoshida et al., within the first $24 \mathrm{~h}$ of the procedure, $50 \%$ of the patients had ASD in transthoracic echocardiography, and $87 \%$ of the patients had ASD in transesophageal echocardiography. ${ }^{[7]}$ Iatrogenic ASD, which occurs after PMBV, usually has a diameter of $0,0.5-1 \mathrm{~cm}$. Defects that are $>1 \mathrm{~cm}$ rarely occur and are associated with large left-to-right shunts. Iatrogenic defects that are $<0.7 \mathrm{~cm}$ have a tendency to close spontaneously within $24 \mathrm{~h} .{ }^{[8]}$ The second scenario for "acquired LS" is spontaneous secundum type ASD development due to progressive left-atrial enlargement and pressure overload in the presence of severe MS. ${ }^{[2]}$

The parameters used to assess the severity of MS are as follows: MVA, mitral valve mean diastolic gradient, and pulmonary arterial pressure. The most commonly used echocardiographic methods for calculating MVA are PHT, planimetric MVA calculation, and continuity equation. ${ }^{\left[{ }^{[}\right]}$ In LS patients, the existence of ASD directs blood flow from the left-to-right atrium, causing diminished blood flow through the mitral valve in the diastole. Diminution of blood flow decreases PHT, causing an underestimation of the severity of MS. For this reason, PHT is inappropriate and not recommended for calculating MVA in LS patients. The appropriate choices for calculating MVA are planimetry and continuity equation. However, in patients with atrial fibrillation, MVA cannot be calculated via continuity equation. ${ }^{[10]}$

LS has a good prognosis if it is diagnosed early. In patients who are diagnosed before the development of right-heart failure or pulmonary hypertension, survival is excellent following mitral valve replacement and ASD closure. However, prognosis will be poor if pulmonary hypertension and right-heart failure exist at the time of diagnosis.

\section{Conclusion}

The purpose of this report is to review the clinical characteristics, echocardiographic diagnosis, and prognosis of LS. LS is a rare diagnosis for most adult cardiologists. This report seeks to help clinicians to better grasp the clinical and echocardiographic characteristics of "acquired LS" presenting in older patients.

\section{Declaration of patient consent}

The authors certify that they have obtained all appropriate patient consent forms. In the form, the patients have given their consent for their images and other clinical information to be reported in the journal. The patients understand that their names and initials will not be published and due efforts will be made to conceal identity, but anonymity cannot be guaranteed.

\section{Financial support and sponsorship}

Nil.

\section{Conflicts of interest}

There are no conflicts of interest.

\section{RefEREnCES}

1. Nagamani AC, Nagesh CM. Lutembacher syndrome. In: Vijayalakshmi IB, Syamasundar Rao P, Chugh R. editors. A Comprehensive Approach to Congenital Heart Diseases. $1^{\text {st }}$ ed. Ch. 64. India: Jaypee Brothers Medical Publisher; 2013. p. 908-16.

2. Ananthasubramaniam K, Iyer G, Karthikeyan V. Giant left atrium secondary to tight mitral stenosis leading to acquired Lutembacher syndrome: A case report with emphasis on role of echocardiography in assessment of lutembacher syndrome. J Am Soc Echocardiogr 2001;14:1033-5.

3. Fadel BM, Hiatt BL, Kerins DM. Isolated rheumatic tricuspid stenosis with reverse Lutembacher's physiology. Echocardiography 1999;16:567-73.

4. Perloff JK. The Clinical Recognition of Congenital Heart Disease. $4^{\text {th }}$ ed. Philadelphia: WB Saunders; 1994. p. 323-8.

5. Olivares-Reyes A, Al-Kamme A. Lutembacher's syndrome with small atrial septal defect diagnosed by transthoracic and transesophageal echocardiography that underwent mitral valve replacement. J Am Soc Echocardiogr 2005;18:1105.

6. Steinbrunn W, Cohn KE, Selzer A. Atrial septal defect associated with mitral stenosis. The Lutembacher syndrome revisited. Am J Med 1970;48:295-302.

7. Yoshida K, Yoshikawa J, Akasaka T, Yamaura Y, Shakudo M, Hozumi T, et al. Assessment of left-to-right atrial shunting after percutaneous mitral valvuloplasty by transesophageal color Doppler flow-mapping. Circulation 1989;80:1521-6.

8. Parro A Jr., Helmcke F, Mahan EF $3^{\text {rd }}$, Nanda NC, Kandath D, Dean LS, et al. Value and limitations of color Doppler echocardiography in the evaluation of percutaneous balloon mitral valvuloplasty for isolated mitral stenosis. Am J Cardiol 1991;67:1261-7.

9. Baumgartner H, Hung J, Bermejo J, Chambers JB, Evangelista A, Griffin BP, et al. Echocardiographic assessment of valve stenosis: EAE/ ASE recommendations for clinical practice. J Am Soc Echocardiogr 2009;22:1-23.

10. Vasan RS, Shrivastava S, Kumar MV. Value and limitations of Doppler echocardiographic determination of mitral valve area in Lutembacher syndrome. J Am Coll Cardiol 1992;20:1362-70. 